\title{
Model of Verbal Communication with Blind Patient: Application in Nursing Appointment
}

\author{
Kátia Nêyla de Freitas Macêdo-Costa1, Lorita Marlena Freitag Pagliuca2*, \\ Antonia Ferreira Alves Sampaio², Paulo César de Almeida2, \\ Cristiana Brasil de Almeida Rebouças ${ }^{2}$ \\ ${ }^{1}$ Department of Nursing, Universidade Federal da Paraíba, Campina Grande, Brazil \\ ${ }^{2}$ Department of Nursing, Universidade Federal do Ceará, Fortaleza, Brazil \\ Email: *pagliuca@ufc.br
}

Received 5 June 2014; revised 20 July 2014; accepted 2 August 2014

Copyright (C) 2014 by authors and Scientific Research Publishing Inc.

This work is licensed under the Creative Commons Attribution International License (CC BY). http://creativecommons.org/licenses/by/4.0/

c) (i) Open Access

\begin{abstract}
It was aimed at validating the applicability of the Model of Verbal Communication with blind people in nursing appointment in the stages of the nursing process. A methodology of quantitative study was used with 30 nurses and 30 blind people who participated in the study, divided in control and experimental groups. 30 nursing appointments took place; they were recorded and analyzed by three judges. The experimental group had excellent performance in following protocol $(95.6 \%)$; taking notes informing the reason for silence (93.4\%); and avoiding long silence (100\%). In interventions, it presented excellence in all the items, in the evaluation stage, there were no bad/terrible actions. In none of the actions the control group presented better performance than the experimental one. The use of the Model is recommended in nursing appointment with blind patient.
\end{abstract}

\section{Keywords}

Communication, Nursing, Visually Impaired Patients, Disabled Patients, Humanization of Assistance

\section{Introduction}

One of the current challenges found by nursing is to offer effective and humanized assistance, conciliating variables such as cost and quality in adequate proportions, independently of the type of the clientele. In a previous study [1], concerning the assistance to blind patients, the verbal communication was a relevant problem identi-

${ }^{*}$ Corresponding author. 
fied in the research, between the nurse and the blind patient during an appointment for diabetes and it emphasizes the scarcity of experience which contemplates this population.

In order to face this challenge, new paths are established in studies regarding the models of communication, which are facilitators for the acquisition of abilities and competences in nursing [2]. Due to the recognition of the peculiarities concerning the communication with the blind patients, which emphasizes verbal and tactile communication, a Model of verbal communication with the blind patient was developed, with the specific purpose to guide the nurse to verbally communicate with these people during their actions. Once made, the Model was evaluated by specialists who recommended its use during the appointment with the blind patient [1].

The elaboration of the Model was developed into seven steps: 1) reception, initial contact between both; 2) data collection concerning the history; 3) diagnosis of nursing; 4) planning; 5) implementation of care; 6) evaluation of nursing; and 7) closing, in which there is the end of communication and consequently, interaction. These moments emphasized the communication according to the steps of the nursing process, so that the nurse could work in a systematized and individualized way, using their critical thought [1].

The communication with the blind patient is made using universal precepts, which contemplate the specificity of such clientele. While the health professional that can see absorbs $80 \%$ of the information of the environment through his look, the blind patient uses the verbal, tactile and olfactive communication; this requires, from the nurse, special abilities to lead effective and efficient communication with the blind patient. The Model of Verbal Communication covers these universal matters of the communication with the blind, and, afterwards, details each predominant action, following the steps of the nursing appointment. So, during the reception, it is possible to observe if the nurse uses communication with sympathy, telling him/her when he has arrived and assuming the function of transmitting communication, informing the activity of the moment, explaining the aim of the appointment material and describes the instrument of register during the steps of diagnosis and planning following the protocol step and, informs the reason of the silence. While he takes notes and avoids prolonged silence.

While she is in the implementation step, the nurse must stimulate the patient to speak, wait for the blind patient to conclude his statement, use common language and prioritize verbal communication, asking for information and suggestions, covering contents on the disease and matters of daily activities, on his personal life, becoming aware of the difficulties of the blind patient, keeping attention to the speaker's emotions. So, the Model, during the steps of evaluation and closing, uses the cooperation of the patient, strengthens the information received, says goodbye, shaking his hand and following him to the door.

When researching the verbal communication with the nursing team, with their attention focused on the attention to the blind patients, it is possible to contribute for better quality assistance. From the above focus presented, it is possible to motivate and subside new investigation. It is necessary to include the relevance for the education of the nurses, under the perspective of social inclusion. So, the aim is at validating the Model of Verbal Communication with the blind patient during the nursing appointment.

\section{Methods}

A methodology of quantitative study was made at the Communication Laboratory and Health from Nursing Department of the Federal University of Ceará (UFC) a venue prepared for experiments of communication, with filming resources, at this venue, a model nurses' office was made in order to discover diabetes. The topic diabetes was chosen for being a problem of public health covered during the education of the nurse, and also because it is a pathology which contributes for lesions in the visual system.

Newly graduated nurses participated in the study, invited through publicizing at the secretaries of the courses when the explanation of the objectives of the research. The criterion of selection of the newly graduated nurses was established once they master basic abilities to lead a nursing appointment, because this is a traditional activity in the process of education of the nurse; blind patients of both eyes and their caregivers were also subjects of the study. Three specialists collaborated analyzing the filming. It is a non-probabilistic sample where the first 15 nurses who agreed to the invitation formed the control group and guided the nursing appointments supported by previous knowledge and the available standard form.

Afterwards, the following 15 nurses who participated formed the experimental group and were prepared to use the Model of Verbal Communication with the blind patient. They received a photocopy of the Model [1], chapters of the theory of Verbal Communication [3] and a period of 15 days for reading. On an appointed date, they had an expositive class on visual impairment and discussion of the texts. Still during the training appoint- 
ments in pairs (40 hours): one blindfolded simulating to be a blind patient and the other as the nurse; soon after that, they switched roles. Each nurse had three simulated appointments, which enabled them to show that they were able to start the data collection, and provided a reflection on the experience of not being able to see. 30 appointments were made, from those 15 were of the control group and 15 of the experimental group.

The appointments were filmed and evaluated by three specialists, trained nurses according to the steps of the Model; of the theory of Verbal Communication and the use of the instrument of analysis of the Model of Verbal Communication with the blind patient [1]. In the evaluation of each filming, the specialists watched the whole filming to understand the whole context and afterwards, after each 30 seconds to register in the instrument of evaluation expressed under these categories: terrible/bad, regular, good and excellent. The specialist did not know the group they were evaluating, whether control or experimental.

Data processed in the Statistical Package for Social Sciences (SPSS) 14.0 and organized in univariate tables with relative frequency and percentages. For the association among the variables and the specialists the chi square test $\left(\chi^{2}\right)$ was used with the maximum probability. The level of significance was established at 5\% [4]. The ethical principles of research with human beings were respected and, the study was approved by Ethics Committee at UFC.

The variables are organized according to the steps of the Model of Verbal Communication, as follows: reception, data collection, diagnosis and nursing planning, implementation of nursing, evaluation and closing.

\section{Results}

Considering 30 filmings (15 control group and 15 experimental) and the evaluation of three specialists, each group of action evaluated received 45 concepts. 23 groups of actions were evaluated, with a total of 1035 .

Within the experimented group, there was an excellent result in five of the six evaluated actions (Table 1). In

Table 1. Comparison of the nursing actions between the control and experimental groups of nurses related to reception and data collection of the patients. Fortaleza, CE, Brazil.

\begin{tabular}{|c|c|c|c|c|c|c|c|c|c|c|}
\hline \multirow{2}{*}{ Action } & \multicolumn{2}{|c|}{ Terrible/Bad } & \multicolumn{2}{|c|}{ Regular } & \multicolumn{2}{|c|}{ Good } & \multicolumn{2}{|c|}{ Excellent } & \multirow[t]{2}{*}{ Test $^{*}$} & \multirow[t]{2}{*}{$\mathbf{P}$} \\
\hline & $\mathbf{N}$ & $\%$ & $\mathbf{N}$ & $\%$ & $\mathbf{N}$ & $\%$ & $\mathbf{N}$ & $\%$ & & \\
\hline \multicolumn{11}{|c|}{ 1. Communication with sympathy } \\
\hline Control & 8 & 17.8 & 8 & 17.8 & 20 & 44.4 & 9 & 20.0 & 47.14 & 0.0001 \\
\hline Experimental & - & - & - & - & 4 & 8.9 & 41 & 91.1 & & \\
\hline \multicolumn{11}{|c|}{ 2. Warning when arrival } \\
\hline Control & 44 & 97.8 & - & - & - & - & 1 & 2.2 & 86.17 & 0.0001 \\
\hline Experimental & - & - & 6 & 13.3 & 17 & 37.8 & 22 & 48.9 & & \\
\hline \multicolumn{11}{|c|}{ 3. Sender of part of the communication } \\
\hline Control & 19 & 42.2 & 16 & 35.6 & 5 & 11.1 & 5 & 11.1 & 54.35 & 0.0001 \\
\hline Experimental & - & - & 1 & 2.2 & 14 & 31.1 & 30 & 66.7 & & \\
\hline \multicolumn{11}{|c|}{ 4. Report moment of the activity } \\
\hline Control & 41 & 91.1 & 3 & 6.7 & 1 & 2.2 & - & - & - & 0.0001 \\
\hline Experimental & - & - & - & - & 9 & 20 & 36 & 80.0 & & \\
\hline \multicolumn{11}{|c|}{ 5. Explain the purpose of the material } \\
\hline Control & 40 & 88.9 & 2 & 4.4 & 3 & 6.7 & - & - & - & 0.0001 \\
\hline Experimental & - & - & 3 & 6.7 & 4 & 8.9 & 38 & 84.4 & & \\
\hline \multicolumn{11}{|c|}{ 6. Describe instrument } \\
\hline Control & 43 & 95.6 & - & - & 2 & 4.4 & - & - & - & 0.0001 \\
\hline Experimental & - & - & 5 & 11.1 & 7 & 15.6 & 33 & 73.3 & & \\
\hline
\end{tabular}

*1) $\chi^{2}$ test; 2) Test of Fisher-Freeman-Halton. 
all the actions, the experimental group presented a better performance than the one under control. And that was highlighted in the communication with sympathy (91.1\%), when explaining how and what for the purpose of the materials (84.4\%) and the description of the instrument they were using (80\%).

In Table 2, it is possible to verify the comparison of the nursing actions between the groups of nurses related to the diagnosis and nursing planning. Following the protocol was not a difficult task for the control group, keeping an average of good (33\%) and excellent (8.9\%); but avoiding silence (64.4\%) and explaining the reason of the silence $(55.6 \%)$ had higher statistical results in the experimental group strengthening the efficacy of the learning of the Model of Communication.

In Table 3, the comparison of the nursing actions between the control and experimental groups of nursing concerning the implementation of nursing process is shown. Besides the positive results in all the items evaluated in the experimental group, the excellence is highlighted when the nurse waits for the blind patient to finish his statement $(91.1 \%)$ being aware of the difficulties of the blind patient (88.9\%), prioritizing the verbal communication (84\%).

Also in all the nursing actions, in Table 4, the experimental group presented a better performance than the control group, highlighting that the nursing professional follows the blind patient to the door (82.2\%) and says goodbye shaking hands (62.2\%). On the other hand, the option terrible/bad had a high rate in the control group in three of the four items as follows: strengthens verbal communication (73.33\%); says goodbye shaking hands (71.1\%) and follows the blind patient to the door (71.1\%).

\section{Discussion}

The experimental group had excellent acting in five of the actions proposed concerning reception of the patient (Table 1). They are, from the highest to the lowest rate, as follows: communication with sympathy (91.1\%); explains the purpose of the material used in the appointment (84.4\%); reports the moment of activity (80\%); describes the instrument (73.3\%); it is the sender of part of the communication (66.7\%). Although the humanized care presents primordial behavior, it seems to be still distant of becoming a unanimous reality. Under the prospective of the health educator and investigator, this professional must focus on the human relations aiming at making the patients participating in the process [5]. In the control group, the nurse showed that he listens a little, talks a lot and does not pay the due attention to the patients under their care. In the appointments of the experimental group, it could be noticed that there was mainly the communication with sympathy. This confirms the differences in the practice facing the use and knowledge on the Model of Verbal Communication.

It is up to the nurse to express herself without ambiguities, he must show herself secure and consistent, present positive feelings to the other, allowing her to be independent and stimulate his autonomy. Besides that he must accept him totally and avoid feelings that represent a threat to the other, independently of the situation experienced.

Table 2. Comparison of the actions of nursing between the control and experimental groups of nurses concerning the diagnosis and nursing planning. Fortaleza, CE, Brazil.

\begin{tabular}{|c|c|c|c|c|c|c|c|c|c|c|}
\hline \multirow{2}{*}{ Action } & \multicolumn{2}{|c|}{ Terrible/Bad } & \multicolumn{2}{|c|}{ Regular } & \multicolumn{2}{|c|}{ Good } & \multicolumn{2}{|c|}{ Excellent } & \multirow[t]{2}{*}{ Test $^{*}$} & \multirow[t]{2}{*}{$\mathbf{P}$} \\
\hline & $\mathbf{N}$ & $\%$ & $\mathbf{N}$ & $\%$ & $\mathbf{N}$ & $\%$ & $\mathbf{N}$ & $\%$ & & \\
\hline \multicolumn{11}{|c|}{ 1. Follows the protocol } \\
\hline Control & 9 & 20 & 17 & 37.8 & 15 & 33.3 & 4 & 8.9 & 25.15 & 0.0001 \\
\hline Experimental & - & - & 2 & 4.4 & 30 & 66.7 & 13 & 28.9 & & \\
\hline \multicolumn{11}{|c|}{ 2. Reports the reason of silence } \\
\hline Control & 45 & 100 & - & - & - & - & - & - & - & 0.0001 \\
\hline Experimental & - & - & 3 & 6.73 & 17 & 37.8 & 25 & 55.6 & & \\
\hline \multicolumn{11}{|l|}{ 3. Avoids silence } \\
\hline Control & 41 & 91.1 & 1 & 2.2 & 1 & 2.2 & 2 & 4.4 & - & 0.0001 \\
\hline Experimental & - & - & - & - & 16 & 35.6 & 29 & 64.4 & & \\
\hline
\end{tabular}

*1) $\chi^{2}$ test; 2) Test of Fisher-Freeman-Halton. 
Table 3. Comparison of the actions of nursing between the control and experimental groups of nurses concerning the implementation of nursing. Fortaleza, CE, Brazil.

\begin{tabular}{|c|c|c|c|c|c|c|c|c|c|c|}
\hline \multirow{2}{*}{ Action } & \multicolumn{2}{|c|}{ Terrible/Bad } & \multicolumn{2}{|c|}{ Regular } & \multicolumn{2}{|c|}{ Good } & \multicolumn{2}{|c|}{ Excellent } & \multirow[t]{2}{*}{ Test $^{*}$} & \multirow[t]{2}{*}{$\mathbf{P}$} \\
\hline & $\mathbf{N}$ & $\%$ & $\mathbf{N}$ & $\%$ & $\mathbf{N}$ & $\%$ & $\mathbf{N}$ & $\%$ & & \\
\hline
\end{tabular}

1. Stimulates the patient to speak

$\begin{array}{ccccccccccc}\text { Control } & 25 & 55.6 & 11 & 24.4 & 8 & 17.8 & 1 & 2.2 & 47.57 & 0.0001 \\ \text { Experimental } & 1 & 2.2 & 6 & 13.3 & 12 & 26.7 & 26 & 57.8 & & \end{array}$

2. Waits for the blind patient to conclude his statement

$\begin{array}{lcccccccccc}\text { Control } & 8 & 17.8 & 13 & 28.9 & 16 & 35.6 & 8 & 17.8 & 50.42 & 0.0001 \\ \text { Experimental } & - & - & - & - & 4 & 8.9 & 41 & 91.1 & & \end{array}$

3. Uses common language

\section{Control}

Experimental

4. Prioritizes verbal communication

$$
\text { Control }
$$

Experimental

5. Requires information/suggestion

Control

6. Contents on diseases

$$
\text { Control }
$$

13

Experimental

7. Matters on daily life

$$
\text { Control }
$$

Experimental

8. Matters on personal life

$$
\text { Control }
$$$$
33
$$

Experimental

9. Is aware of the difficulties of the blind patient

$$
\text { Control }
$$$$
24
$$

Experimental

$-$

10. Pays attention to the speaker's emotions

$\begin{array}{ccccccccccc}\text { Control } & 10 & 22.2 & 21 & 46.7 & 11 & 24.4 & 3 & 6.7 & 56.97 & 0.0001 \\ \text { Experimental } & - & - & - & - & 11 & 24.4 & 34 & 75.6 & & \end{array}$

*1) $\chi^{2}$ test; 2) Test of Fisher-Freeman-Halton.

$\begin{array}{lllllllll}2.2 & 8 & 17.8 & 23 & 51.1 & 13 & 28.9 & - & 0.0001 \\ - & - & - & 13 & 28.9 & 32 & 71.1 & & \end{array}$

$\begin{array}{ccccccccc}35.6 & 12 & 26.7 & 9 & 20.0 & 8 & 17.8 & 38.37 & 0.0001 \\ - & 1 & 2.2 & 16 & 35.6 & 28 & 62.2 & & \end{array}$

28.9

$13 \quad 28.9$

$41.00 \quad 0.0001$

$\begin{array}{llllll}1 & 2.2 & 19 & 42.2 & 16 & 35.6\end{array}$

$\begin{array}{ccccccc}71.1 & 9 & 20 & 3 & 6.7 & 1 & 2.2 \\ - & 3 & 6.7 & 18 & 40 & 24 & 53.3\end{array}$

66.87

0.0001

73.3

7

$15.6 \quad 5$

11.1

63.26

0.0001

$\begin{array}{llllll}4 & 8.9 & 17 & 37.8 & 24 & 53.3\end{array}$

53.3

$10 \quad 22$

9

20.

2

4.4

69.52

0.0001

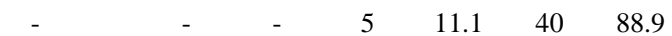


Table 4. Comparison of the nursing actions between the control and experimental groups concerning the evaluation of nursing and closing. Fortaleza, CE, Brazil.

\begin{tabular}{|c|c|c|c|c|c|c|c|c|c|c|}
\hline \multirow{2}{*}{ Action } & \multicolumn{2}{|c|}{ Terrible/Bad } & \multicolumn{2}{|c|}{ Regular } & \multicolumn{2}{|c|}{ Good } & \multicolumn{2}{|c|}{ Excellent } & \multirow[t]{2}{*}{ Test ${ }^{*}$} & \multirow[t]{2}{*}{$\mathbf{P}$} \\
\hline & $\mathbf{N}$ & $\%$ & $\mathbf{N}$ & $\%$ & $\mathbf{N}$ & $\%$ & $\mathbf{N}$ & $\%$ & & \\
\hline \multicolumn{11}{|c|}{ 1. Counts on the cooperation of the patient } \\
\hline Control & 14 & 31.1 & 17 & 37.8 & 12 & 26.7 & 2 & 4.4 & 58.45 & 0.0001 \\
\hline Experimental & - & - & - & - & 12 & 26.7 & 25 & 55.6 & & \\
\hline \multicolumn{11}{|c|}{ 2. Strengthens the verbal communication } \\
\hline Control & 33 & 73.33 & 7 & 15.6 & 3 & 6.7 & 2 & 4.4 & 43.15 & 0.0001 \\
\hline Experimental & 8 & 17.7 & 6 & 13.3 & 12 & 26.7 & 19 & 42.2 & & \\
\hline \multicolumn{11}{|c|}{ 3. Says goodbye speaking and shaking the hands } \\
\hline Control & 32 & 71.1 & 2 & 4.4 & 8 & 17.8 & 3 & 6.7 & 54.30 & 0.0001 \\
\hline Experimental & 3 & 6.7 & 9 & 20.0 & 5 & 11.1 & 28 & 62.2 & & \\
\hline \multicolumn{11}{|c|}{ 4. Follows the blind patient to the door } \\
\hline Control & 32 & 71.1 & 5 & 11.1 & 7 & 15.6 & 1 & 2.2 & 71.17 & 0.0001 \\
\hline Experimental & - & - & - & - & 8 & 17.8 & 37 & 82.2 & & \\
\hline
\end{tabular}

*1) $\chi^{2}$ test; 2) Test of Fisher-Freeman-Halton.

When investigating the death of a terminal patient at home, some impotence and negative feelings were noticed by the nurses in the interactions with the family members. Actually the interpersonal communication was inexistent, due to the fact that they did not know how to cope with the situation, many times acting centered on the techniques which still permeate the care in the phases of the vital cycle from birth to death [6]. This situation is repeated when the nurse feels unable to interact with blind patient, as it is evident in this study.

In order to reach a satisfactory and humanized communication the nurse must involve herself and believe that her presence is very important concerning the performers of technical procedures [7], once not always the technical knowledge does not work so well facing situations of stress such as the subjective knowledge reviewed in the communication. Standing beside the patient to listen to him is a therapy action which should be recognized [8]. The effectiveness of the communication is supported by the empathy and respect established between the subjects concerning care, by his knowledge and by his condition of participant and the process of communication. In a previous study [9], in the hospital dynamics it was possible to identify that many professionals manage to have more effectiveness in the care exactly for keeping an empathetic relation.

Communicating is not something simple, it requires several competences such as the abilities to listen, a valuable instrument in the development of a relation of help, and the capacity to avoid directivity and let the person himself conduct the contents of his communication [6]-[10]. The results of this study allow considering the competency in interpersonal communication with the blind patient as a fundamental ability to be acquired by the nurse. Furthermore, it will provide a conscious, true and transforming care. It is necessary to exercise the capacity of listening, in the experimental group this happened when the nurse acted as the sender of part of the communication, showing balance between the speakers.

During the assistance to the blind patient it is up to the nurse to describe in detail the procedure before an intervention in an oral and clear manner. It is up to him to mention his name, function, which procedure he will perform, how he will do it and its purpose. This provides security, tranquility and familiarity to the patient.

The communication occurs more easily when there is clear and objective information; there are explanations on the condition of the patient and on the equipment being used. It is indispensable to the families and patients to communicate with the health team, in order to receive orientations and clarify doubts and also to have their needs of comfort attended to, and to receive caring words and attention [11]. All these actions must be developed in the several contexts of acting of the nurse, not only in nursing appointments, but also during the home visits and at the hospital units. 
A study investigated the opinion of the nurses on their communication when informing the diagnosis and prognosis of the serious disease to the patient and his family, and revealed that those have frequent difficulty to communicate that to the patient, with the family members this difficulty persists, but at a lower level. The ethical principles concerning integrity, dignity and autonomy of the patient were discussed, contextualized in the culture of the patient and the health professional [12].

In this study, the statement of the blind patient was very interesting when they touched the instrument used for the consultation of screening. They reported that when they were assisted before, they had never touched the objects used by the health team; they did not understand the use of each one nor their functioning. Here the nurses explained how these instruments helped in the assistance in a ludic and simple language.

According to what was observed, the lack of effective communication implies in inadequate care, which is then defined as mere routines of procedures, the doing for just doing and so the nurses cannot reach all their potential [13].

Still analyzing the control group (Table 1), the item warns the patient when the nurses arrives or comes close to him, happened only in one circumstance. In $97.8 \%$ of interactions where the nurse left the blind patient to search for some material or perform another activity away from the place of the interaction, they were made in silence: the nurse left and came back without uttering any word. Due to specificities of the blind patient, he perceives the absence of the other but does not understand the reason; this might characterize a fragile communication without a professional commitment.

Concerning the diagnosis and the nursing plans (Table 2), the nurses of the experimental group presented some good and excellent rates in the following actions: Follow the protocol (95.6\%); make notes informing the reason of the silence (93.4\%); and avoid prolonged silenced (100\%). In the control group, a terrible result was observed in two items: Notes (not) informing the reason of the silence (100\%) nor the reasons for not avoiding the prolonged silence (91\%). According to what was noticed, the non-verbal communication among the health professionals happened when the professionals turn their faces and keep quiet. Even without words the body speaks and expresses a silent language, the non-verbal communication, which is difficult for the blind patient to understand.

The gestures indicate the way that the body speaks without words, attitude used frequently in the daily work of the professional nurse. But the blind patient does not perceive these gestures, and so this prevents him from evaluating the actions through the gestures. The literature reports that the silence, the mute space between one word and another, between a look and an action, can be an opportunity for something unprecedented to happen. In it, there might come the moment to make the encounter between the professional and the patient concrete [5]-[14].

So it is essential that the professional knows how to use silence therapeutically, considered one of the hardest techniques to be put into practice, once in general the nurse has a series of questions to ask the patient. The silence that is used by the professional, just by itself, encourages the patient to talk, transmits him the expectation that he can talk and is going to be heard; offers time both for the patient as well as for the nurse to organize and evaluate their thoughts and feelings [15]. But the prolonged silence must be avoided with these people once this can cause a situation of anxiety, because the blind patient cannot see what is happening in the environment or if the professional is away for some time. These situations must be preceded by an explanation.

Concerning the implementation of the intervention of nursing (Table 3), it showed excellence by the experimental group in all the items once the professional waits for the blind to conclude his statement (91.1\%); is aware of the difficulties of the blind patient (88.9\%); prioritizes verbal communication (84.4\%); pays attention to the reactions of the blind (84.4\%); and to the emotions of the speaker (75.6\%); uses common language (71.1\%); asks for information/suggestion (62.2\%); stimulates the patient to talk (57.8\%); talks about matters on the daily life (53.3\%) and talks about matters on personal life (53.3\%).

The persons who are able to see use non-verbal communication more predominantly, as it was noticed in a study of a communication of the HIV mother when taking care of her child up to six months of life, when she uses these forms of communication to show affection. Blind parents when describing what they did to breastfeed, bathe, feed, prevent domestic accidents and give medicine to their children they use the tact, the hearing and the smell. That is, the blind patients use predominantly hearing as verbal communication and complementary to tact, away from non-verbal communication. The health professional must have the abilities to perceive these differences and intervene effectively [16] [17]. On the other hand, a blind mother with motor impairment, filmed while breastfeeding, showed scarce non-verbal communication, once she did not show her face to the child. The 
manifestation of tenderness and affection to her son was provided by words with emotional connotation [18].

During the performance of care it is important to perform all these actions found in the experimental group, so that both speakers get involved in the process of effective communication. When listening to the patient, the nurse must be aware not to judge the contents of the thought being expressed, it must concentrate on the statement of the blind patient, reflect and understand the contents of the message and be aware to his reactions and emotions. The nurse must encourage verbalization, listen, be comprehensive and provide information, which can relieve his concerns. According to what the literature mentions, the nurse must ask for clarifications on the meaning of the content expressed by the blind patient; once he has this knowledge and the knowledge of what was transmitted at the moment, the professional becomes more secure to stimulate the verbal manifestation of the feelings and other contents [15].

Caring is applying scientific knowledge in the day-by-day experiences, associated to the ability to use emotion and sensibility as the bases of communication to perform care considering the patient as a human being to be respected [14]. Although all the professionals are inserted in the same scenario, the language used by the social actors depends on the inter relations between the sender and the recipient on the social and professional situation in which it happens. Generally speaking in the process of professional communication, the technical language predominates. The initials and abbreviations are also used as a resource to make writing and speaking faster. The language suggested in the daily experiences of the professional involves symbols and meanings coming from practice.

However, language can be a source of misunderstanding, above all the technical and scientific language because it is not within the domain of the patient, he does not duly understand the language adopted by the health professionals. So he can make wrong interpretation of the care rendered [14]. This study confirms these statements when it makes evident the validity of the Model when the nurses of the experimental groups privilege the use of common language, emerging a reflection on the importance of using in the daily experiences a type of language that is understood not only by the professionals but also by patient, the society and the family.

When the nurse is inserted in the context, she is able to offer assistance according to the needs of the patient, using specialized reference which keeps and respects the sympathetic relations [6]. Social life is constituted by language, not the language of the grammar scholars and the linguistics, but the language of the daily life [14]. That is, even during the professional function, the nurse must balance the technical information on matters regarding the daily and personal life of the blind patient, generating a humanized relationship without losing the focus of the purpose of the consultation.

The analysis of the verbal and non-verbal communication among the mother, child and nurse triad shows the mother as the recipient with the nurse, that is, the nurse stimulates the mother to express herself and waits the necessary time for that, the contents of communication of the mother sometimes express doubts and requests orientations on how to take care of her child. In the non-verbal communication, the nearness between mother and child prevails and the personal distance between mother and nurse. It is worth highlighting that in this study the nurse has been prepared for the use of verbal and non-verbal communication with the blind patient [19].

Facing the practice of dialogue in all and any interpersonal relation language must be observed as a main form of communication and information on knowledge, ideas, beliefs and emotions. The dialogue in the process of social relationship must be manifested in a gentle and courteous way, once the way you speak brings compatible results to its nature; the collective experience is determined to assure health to the group and above all enrich the subject who is willing to dedicate himself to it, whether informal or informal meetings; conversation is used as a means to make yourself understood. All of this makes interpersonal relations easier whether they are technical, academic, social, it does not matter; conversations are the link which activates sociability [20].

Evaluating nursing consists in following the patient responses to the prescribed and implemented care, through notes, direct observation, as well as the report as the patient [1]-[15]. As to the evaluation and closing of the consultation (Table 4), the option excellent had a high rate in the experimental group. Therefore, the communicative participations of the blind patient must be stimulated in order to reach the pre-established targets. Besides that, the lack of experience not trained in communicating among themselves was evident, once only $2.2 \%$ had excellence in the function to follow the blind patient up to the door, which is an indispensable fact for these people, and $6.6 \%$ bid goodbye talking and shaking hands with the blind patient.

Spatial orientations occur from the corporal consciousness and the occupation of space happens through mobility [21]. That is why there is the concern with the orientation and mobility of the blind within the health institutions, and unknown environment. So when saying goodbye to the blind patient the nurse must be aware of the 
need to take him to the office door and orientate him in his exit of the health unit, especially if it is the first contact of the blind patient with that venue. The spatial orientation is the ability of the subject to perceive the environment surrounding him, establishing the corporal spatial and time relations with that environment through reminiscent feelings. Being a facilitating support in his social integration the nurse must provide autonomy in locomotion, self-confidence, increase of high self-esteem and intelligence [21].

\section{Conclusion}

In this study, it became evident that the nurse did not receive abilities to establish the effective communication with the blind patient in his education. The group which received specific training had a better statistically experimental performance in all the points approached in the model, had excellent performance in following protocol (95.6\%); taking notes informing the reason for silence (93.4\%); and avoiding long silence (100\%). In interventions, it presented excellence in all the items, in the evaluation stage, there were no bad/terrible actions. Through the results obtained, it is possible to confirm that the Model of Verbal Communication with the Blind patient is effective in a nursing appointment. Thus, it is recommended its use when taking care of the blind patient and the development of researches with the same in other contexts of professional practice in nursing appointment.

\section{Conflict of Interests}

There was no conflict of interests.

\section{References}

[1] Macêdo-Costa, K.N.F., Pagliuca, L.M.F., Almeida, P.C. and Cardoso, M.V.L.M.L. (2009) Aspects of Verbal Communication between Nurses and the Visually Impaired. Revista Rene, 10, 29-36. http://www.revistarene.ufc.br/vol10n2_html_site/a03v10n2.htm

[2] Spagnuolo, R.S. and Pereira, M.L.T. (2007) Práticas de saúde em enfermagem e comunicação: um estudo de revisão da literatura. Ciência \& Saúde Coletiva, 12, 1603-1610. http://www.scielo.br/pdf/csc/v12n6/v12n6a19.pdf http://dx.doi.org/10.1590/S1413-81232007000600021

[3] Jakobson, R. (2001) Linguística e comunicação. Cultrix, São Paulo.

[4] Gorenstein, C., Andrade, L.H.S.G. and Zuardi, A.W. (2001) Escalas de avaliação clínica em psiquiatria e psicofarmacologia. Lemos Editorial, São Paulo.

[5] Haidet, P. (2010) No Longer Silent: On Becoming an Active Patient. Health Communication, 25, 195-197. http://www.tandfonline.com/doi/pdf/10.1080/10410230903544993\#.U5B5InbPZh4 http://dx.doi.org/10.1080/10410230903544993

[6] Linderholm, M. and Friedrichsen, M.A. (2010) Desire to Be Seen: Family Caregivers’ Experiences of Their Caring Role in Palliative Home Care. Cancer Nursing, 33, 28-36. http://www.ncbi.nlm.nih.gov/pubmed/19926979 http://dx.doi.org/10.1097/NCC.0b013e3181af4f61

[7] Araújo, I.M.A., Silva, R.M., Bonfim, I.M. and Fernandes, A.F.C. (2010) Nursing Communication in Nursing Care to Mastectomized Women: A Grounded Theory Study. Revista Latino-Americana de Enfermagem, 18, 54-60. http://www.scielo.br/pdf/rlae/v18n1/09.pdf http://dx.doi.org/10.1590/S0104-11692010000100009

[8] Pontes, A.C., Leitão, I.M.T.A. and Ramos I.C. (2008) Therapeutic Communication in Nursing: Essential Instrument of Care. Revista Brasileira de Enfermagem, 61, 312-318. http://www.scielo.br/pdf/reben/v61n3/a06v61n3.pdf http://dx.doi.org/10.1590/S0034-71672008000300006

[9] Ferreira, M.A.A. (2006) Communication in Care: A Fundamental Task in Nursing. Revista Brasileira de Enfermagem, 59, 327-330. http://www.scielo.br/pdf/reben/v59n3/a14v59n3.pdf http://dx.doi.org/10.1590/S0034-71672006000300014

[10] Braga, E.M. and Silva, M.J.P. (2007) Competent Communication-A View of Nurse Experts in Communication. Acta Paulista Enfermagem. 20, 410-414. http://www.scielo.br/pdf/ape/v20n4/en_03 http://dx.doi.org/10.1590/S0103-21002007000400004

[11] Inaba, L.C., Silva, M.J.P. and Telles, S.C.R. (2005) The Critical Patient and Communication: The Vision of the Family Regarding the Nursing Team. Revista da Escola de Enfermagem da USP, 39, 423-429.

http://www.scielo.br/pdf/reeusp/v39n4/07.pdf http://dx.doi.org/10.1590/S0080-62342005000400008

[12] Mendes, I.A.C., Hayashida, M., Trevizan, M.A., Godoy, S., Leite, J.L. and Nogueira, M.S. (2007) Diagnóstico e 
prognóstico graves: Dificuldades para comunicar ao paciente e à família. Ciência Cuidado e Saúde, 6, 300-304. http://periodicos.uem.br/ojs/index.php/CiencCuidSaude/article/view/3989/2720

[13] O’Leary, K.J., Thompson, J.A., Landler, M.P., Kulkarni, N., Haviley, C., Hahn K., et al. (2010) Patterns of NursePhysician Communication and Agreement on the Plan of Care. Quality Safety Health Care, 19, 95-98. http://qualitysafety.bmj.com/content/19/3/195.full.pdf+html http://dx.doi.org/10.1136/qshc.2008.030221

[14] Cavalcanti, A.S.D. and Coelho, M.J. (2007) A linguagem como ferramenta do cuidado do enfermeiro em cirurgia cardíaca. Escola Anna Nery, 11, 220-226. http://www.scielo.br/pdf/ean/v11n2/v11n2a06.pdf

[15] Stefanelli, M.G. and Carvalho, E.C. (2007) A comunicação nos diferentes contextos da enfermagem. Manole, São Paulo.

[16] Paiva, S.S., Galvã, M.T.G., Pagliuca, L.M.F. and Almeida, P.C. (2010) Non-Verbal Mother-Child Communication in Conditions of Maternal HIV in an Experimental Environment. Revista Latino-Americana de Enfermagem, 18, 41-47. http://www.scielo.br/pdf/rlae/v18n1/07.pdf http://dx.doi.org/10.1590/S0104-11692010000100007

[17] Pagliuca, L.M.F., Uchoa, R.S. and Machado, M.M.T. (2009) Blind Parents: Their Experience in Care for Their Children. Revista Latino-Americana de Enfermagem, 17, 27127-27124. http://dx.doi.org/10.1590/S0104-11692009000200021

[18] Pagliuca, L.M.F., Barbosa, G.O.L., Wanderley, L.D. and Oliveira, P.M.P. (2011) Analysis of the Verbal and NonVerbal Communication of a Blind Mother with Motor Impairment during Breastfeeding. Revista Brasileira de Enfermagem, 64, 431-437.

[19] Wanderley, L.D., Barbosa, G.O.L., Pagliuca, L.M.F., Oliveira, P.M.P., Almeida, P.C. and Rebouças, C.B.A. (2010) Comunicação verbal e não-verbal de mãe cega durante a higiene corporal da criança. Revista Rene, 11, 150-159. http://www.revistarene.ufc.br/edicaoespecial/a17v11esp_n4.pdf

[20] Braga, J.P., Dyniewicz, A.M. and Campos, O. (2008) Tendências no relacionamento humano na área da saúde. Cogitare Enfermagem, 13, 290-295. http://ojs.c3sl.ufpr.br/ojs/index.php/cogitare/article/view/12522/8577

[21] Basto, L.S.C. and Gaio, R.C. (2010) Técnicas de orientação e mobilidade para pessoas cegas: Reflexões na perspectiva da educação física. Movimento e Percepção, 11, 120-147.

http://www.researchgate.net/publication/43763856_Tcnicas_de_orientao_e_mobilidade_para_pessoas_cegas_reflexes_ na_perspectiva_da_educao_fsica 
Scientific Research Publishing (SCIRP) is one of the largest Open Access journal publishers. It is currently publishing more than 200 open access, online, peer-reviewed journals covering a wide range of academic disciplines. SCIRP serves the worldwide academic communities and contributes to the progress and application of science with its publication.

Other selected journals from SCIRP are listed as below. Submit your manuscript to us via either submit@scirp.org or Online Submission Portal.
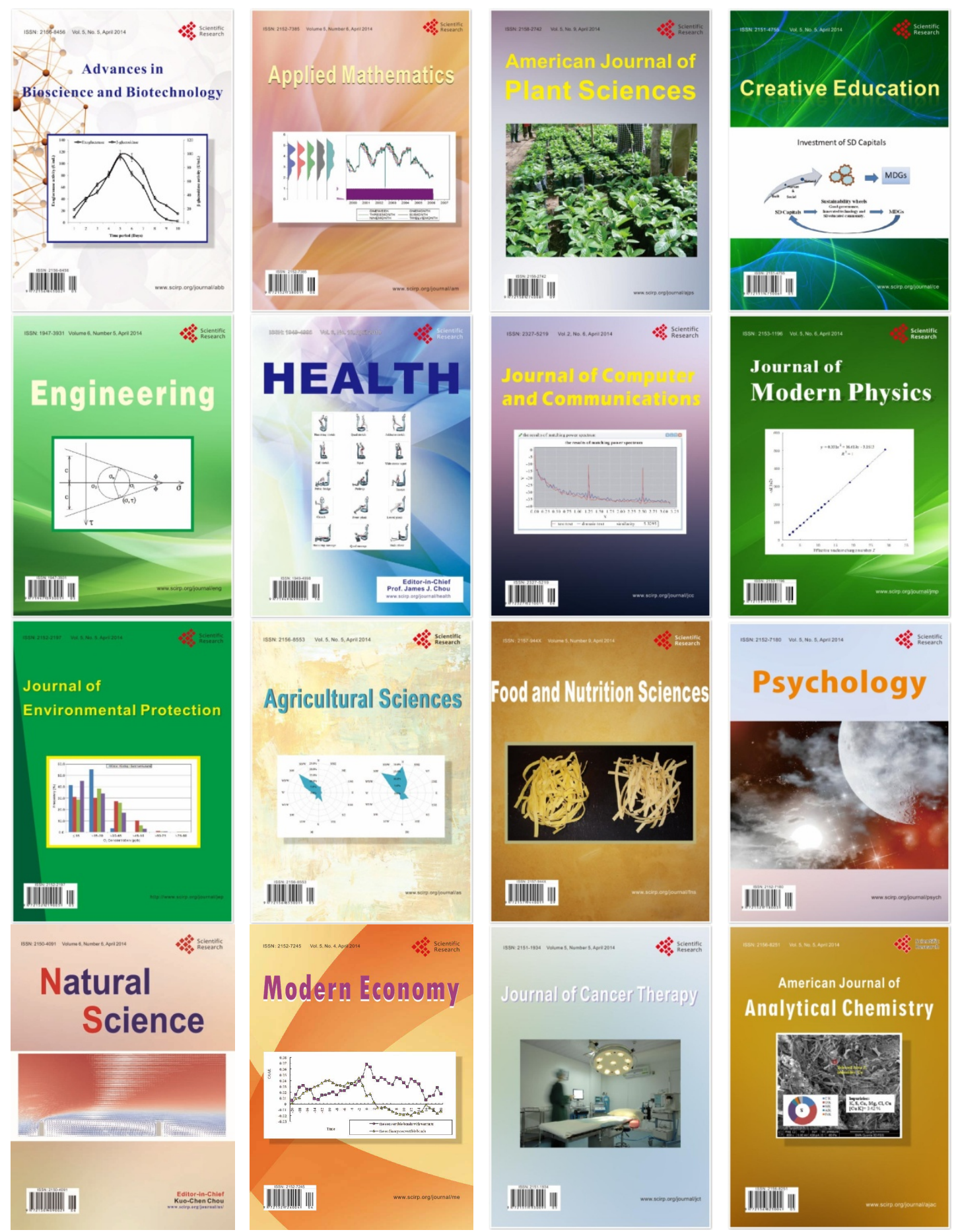